\title{
Experimental Investigation of Dynamic Characteristics of Multilayer PU Foam Sandwich Panels
}

\author{
Sourabha S. Havaldar ${ }^{*}$, Ramesh S. Sharma \\ Department of Mechanical Engineering, R V College of Engineering, Bangalore, India \\ Email: "shsourabha@rediffmail.com
}

Received June 3, 2013; revised July 11, 2013; accepted July 24, 2013

Copyright (C) 2013 Sourabha S. Havaldar, Ramesh S. Sharma. This is an open access article distributed under the Creative Commons Attribution License, which permits unrestricted use, distribution, and reproduction in any medium, provided the original work is properly cited.

\begin{abstract}
In the present work the dynamic characteristics of Multilayer Polyurethane foam glass/fiber composite sandwich panels have been determined through Experimental Investigations. Using a Multilayer Polyurethane foam sandwich panel with rectangular cross-section, the natural frequencies, mode shapes and the damping ratio of sandwich panels were evaluated. Three types of boundary conditions were simulated namely, C-F-F-F (Clamped Free-Free-Free), C-F-C-F (Clamped-Free-Clamped-Free), C-C-C-C-(Clamped-Clamped-Clamped-Clamped). Experimental modal tests were conducted on sandwich panels with available polyurethane foam of densities $56 \mathrm{~kg} / \mathrm{m}^{3}, 82 \mathrm{~kg} / \mathrm{m}^{3}$ and $289 \mathrm{~kg} / \mathrm{m}^{3}$. The traditional "strike method" has been used to measure vibration properties. The modal characteristics of the specimens have been obtained by studying their impulse response. Each specimen has been subjected to impulses through a hard tipped hammer which is provided with a force transducer and the response has been measured through the accelerometer. The impulse and the response are processed through a computer aided FFT Analyzing test system in order to extract the modal parameters. Finite Element modeling was carried out treating the facing and core as orthotropic with different elastic constants as recommended in the literature. The experimental results were validated with FEA and were found to be in good agreement. The results obtained through modal test on multilayer sandwich panels are presented. They indicate a significant variation in the dynamic parameters in case of multilayer sandwich panels for the same core density as compared to a monolayer sandwich panel.
\end{abstract}

Keywords: Multilayer; Sandwich Panel; Modal Testing; Impulse; Frequency; PUF

\section{Introduction}

Sandwich structures that employ a polyurethane foam core between two relatively thin skins of glass fiber reinforced plastics are desirable in several engineering applications that require high strength-to-weight ratios with good damping capacity. Because of their ability to absorb large amounts of energy, they are also often used as a "cushion" against external loads. Polyurethane foam sandwich structures are currently being used in many engineering applications, in local automotives, and within and outside of aerospace engineering. Light weight polyurethane foam materials can be used in the construction of composite panels, shells, and tubes with high structural efficiency. In recent years, research pertaining to polyurethane foam sandwich structures has focused on effective numerical modeling methods, vibration proper-

${ }^{*}$ Corresponding author. ties, crash-worthiness, damage, and failure and impact response [1,2]. A number of researchers have investigated the dynamic behavior of sandwich panels. Mohammed F. Aly et al. [3], have experimentally investigated the dynamic characteristics of laminated composite beams, in which they have conducted impact experimental tests. In these tests, FRFs (Frequency Response Functions) were determined that relate the response given by the specimen when loaded with a signal, allowing for the determination of natural frequencies. Ziad K. Awad et al. [4] have investigated frequency characteristics of GFRP/ Phenolic sandwich beams experimentally by strike method using the LMS Test-lab instrument, in which the tests were carried out for three different boundary conditions. Jafar Eskandari \& Jam, et al. [5] developed theories for the dynamic response of sandwich panels. Zhuang Li [6] emphasized more on introduction of viscoelastic core layer between two face sheets that can produce a 
sandwich structure with high damping. Jian Xiong et al. [7], have studied the mechanical response and failure mechanisms of two-layer carbon fiber composite sandwich panels with pyramidal truss cores under uniform quasistatic compressive loading and low-speed concentrated impact, as an initial step in understanding the performance of multi-layer composite panels. Marco Matter et al. [8] have developed a mixed numerical-experimental identification procedure for estimating the storage and loss properties in sandwich structures with a soft core. The method uses at the experimental level, a precise measurement setup with an electro-dynamic shaker and a scanning laser interferometer, and at the computational level, an original structurally damped shell finite element model derived from the higher-order shear deformation theory with piecewise linear functions for the through-thethickness displacement. Qunli Liu and Yi Zhao [9] have studied the vibration of a sandwich panel with two identical isotropic facesheets and with an orthotropic core. The governing partial differential equation was derived using a variational principle and predicted the natural frequencies of a rectangular sandwich panel proposed analytical model. The effects of the structural and material parameters such as core anisotropy, core density, and facesheet thickness on natural frequencies were discussed. Amir Shahdin et al. [10] carried out compression tests in order to calculate the compressive modulus for the sandwich honeycomb, foam and entangled specimens. Hualin Fan et al. [11] fabricated multi-layered panels by stacking thin monolayer panels to improve the energy absorption ability of the woven textile sandwich. Quasistatic compression experiments were conducted to get the stress-strain curves and to reveal the energy absorption mechanism. Dharmasena et al. [12], and Wadley et al. [13] found that FRP multi-layered sandwich structure were effective at resisting dispersing high intensity impact impulses, as well as reducing the peak pressure transmitted to the underlying structure. The dynamic crush response of a low relative density, multilayered corrugated core is investigated by combining insights from experiments and 3D finite element simulations.

S. C. Mohanty [14], proposed a finite element for modeling a generalized multi-layered symmetric sandwich beam, with alternate elastic and viscoelastic layers. The detailed derivation of the element mass and stiffness matrices have been presented. He presented numerical results for three, five and seven layered viscoelastic core material. He proposed an element that can be used for vibration analysis of sandwich beams having any number of layers. Nakra [15] explained about the use of vibration control of machines and structures incorporating viscoelastic materials in suitable arrangement as an important aspect of investigation. Multilayered sandwich like struc- tures can be used in aircraft structures and other applications, such as robot arms for effective vibration control.

Much of the literature is related to one of the attributes (high strength/weight or increased energy absorption) as mentioned above. Also, most of the available literature discusses about the dynamic parameters of single layer polyurethane foam sandwich beams. With regard to the development of a multilayer polyurethane foam sandwich panel, one issue that has been overlooked is the scaling of multilayer polyurethane foams properties with respect to different foam densities. The variation in staking of different foam densities (as core of the sandwich panels) may have a significant large influence on the dynamic properties of sandwich panels.

The present paper expands upon this study. The results from the experimental program are presented and discussed. Of interest in this study is the effect of multilayer foams with different densities on the fundamental frequency of sandwich panels.

\section{Experimental Methodology}

\subsection{Fabrication of Multilayer Polyurethane Foam Sandwich Panels}

FRP polyurethane foam sandwich panels have been fabricated through vacuum bag molding technique as shown in Figure 1. Vacuum is used to eliminate the entrapped air and excess resin. The adhesive used is epoxy resin LY 556 mixed with hardener HY 951 in the weight ratio of 10:1. After ensuring the surface is clean and free from foreign particles, a coat of release agent is applied. Subsequently, two layers of polyurethane foams of different densities were bonded using the same adhesive to obtain three combinations of multilayer sandwich panels as shown in Figure 2. The sandwich panels were cured for three hours at a temperature of $100^{\circ} \mathrm{C}$.

Cured sandwich panels were further prepared for different boundary conditions namely, C-F-F-F (ClampedFree-Free-Free), C-F-C-F (Clamped-Free-Clamped-Free) and C-C-C-C (Clamped-Clamped-Clamped-Clamped) conditions.

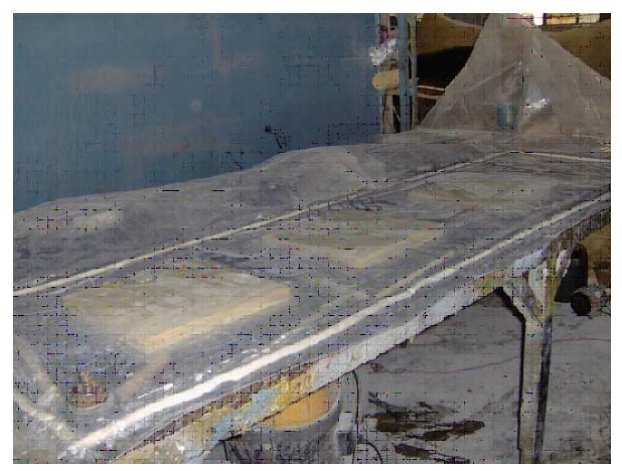

Figure 1. Vacuum pressure application. 


\subsection{Specimen Details}

For the preparation of multilayer sandwich panels, three different density polyurethane foams of $56 \mathrm{Kg} / \mathrm{m}^{3}, 82$ $\mathrm{Kg} / \mathrm{m}^{3}, 289 \mathrm{Kg} / \mathrm{m}^{3}$ were considered. Face sheets made of bi-woven glass cloth (considered as orthotropic material) are used and their elastic properties are as shown in Table 1. In all, 27 sandwich panels were prepared with dimensions maintained at $160 \mathrm{~mm} \times 160 \mathrm{~mm} \times 15 \mathrm{~mm}$ for the three boundary conditions viz., C-F-F-F, C-F-C-F and C-C-C-C. A multilayer sandwich panel after fabrication (at Reinforced Plastics Industries, Bangalore) is as shown in Figure 3. Sandwich panel specimens are designated as mentioned in Table 2.

\subsection{Modal Test Method}

The modal characteristics of the specimen have been obtained by studying its impulse response. The specimen has been subjected to impulses through a hard tipped

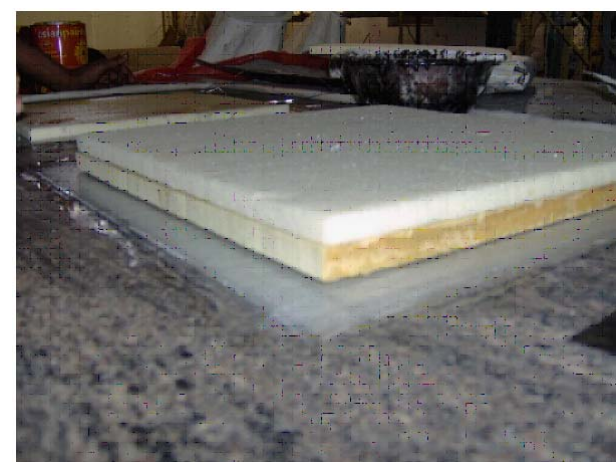

Figure 2. Preparation of multilayered sandwich panel.

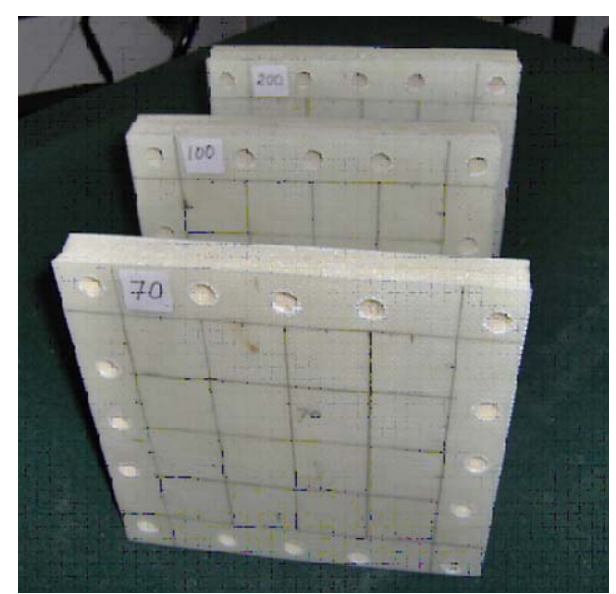

Figure 3. Multilayer sandwich panels.

Table 1. Elastic properties of the bi-woven FRP facings.

\begin{tabular}{ccccccccc}
\hline $\begin{array}{c}E_{1} \\
(\mathrm{GPa})\end{array}$ & $\begin{array}{c}E_{2} \\
(\mathrm{GPa})\end{array}$ & $\begin{array}{c}E_{3} \\
(\mathrm{GPa})\end{array}$ & $\begin{array}{c}G_{12} \\
(\mathrm{GPa})\end{array}$ & $\begin{array}{c}G_{23} \\
(\mathrm{GPa})\end{array}$ & $\begin{array}{c}G_{13} \\
(\mathrm{GPa})\end{array}$ & $v_{12}$ & $v_{23}$ & $v_{13}$ \\
\hline 16.84 & 16.84 & 7.78 & 2.46 & 2.38 & 2.38 & 0.15 & 0.49 & 0.49 \\
\hline
\end{tabular}

Table 2. Specimen designation.

\begin{tabular}{|c|c|c|}
\hline Sl. No. & Specimen Designation & Boundary Conditions \\
\hline \multicolumn{3}{|c|}{ [All ends fixed] } \\
\hline 1 & A0 & PUF-56 \\
\hline 2 & B0 & PUF-82 \\
\hline 3 & $\mathrm{CO}$ & PUF-289 \\
\hline 4 & $\mathrm{AOBO}$ & PUF-56 + PUF-82 \\
\hline 5 & BOAO & PUF-82 + PUF-56 \\
\hline 6 & $\mathrm{AOCO}$ & PUF-56 + PUF-289 \\
\hline \multicolumn{3}{|c|}{ [Two ends fixed] } \\
\hline 10 & A1 & PUF-56 \\
\hline 11 & B1 & PUF-82 \\
\hline 12 & $\mathrm{C} 1$ & PUF-289 \\
\hline 13 & A1B1 & PUF-56 + PUF-82 \\
\hline 14 & $\mathrm{~B} 1 \mathrm{~A} 1$ & PUF-82 + PUF-56 \\
\hline 15 & $\mathrm{~A} 1 \mathrm{C} 1$ & PUF-56 + PUF-289 \\
\hline \multicolumn{3}{|c|}{ [One ends fixed] } \\
\hline 19 & $\mathrm{~A} 2$ & PUF-56 \\
\hline 20 & B2 & PUF-82 \\
\hline 21 & $\mathrm{C} 2$ & PUF-289 \\
\hline 22 & $\mathrm{~A} 2 \mathrm{~B} 2$ & PUF-56 + PUF-82 \\
\hline 23 & $\mathrm{~B} 2 \mathrm{~A} 2$ & PUF-82 + PUF-56 \\
\hline 24 & $\mathrm{~A} 2 \mathrm{C} 2$ & PUF-56 + PUF-289 \\
\hline
\end{tabular}

hammer that is provided with a force transducer (PCB make) with a sensitivity of $2.25 \mathrm{mV} / \mathrm{N}$. The response has been measured through the accelerometer (PCB make) with an accelerometer of sensitivity $10 \mathrm{mV} / \mathrm{g}$. The impulse and the response are processed on a computer aided FFT analyzer test system in order to extract the modal parameters with the help of a built-in software.

The sandwich specimen has been subjected to impulses at 25 station locations. The response has been measured by placing the accelerometer at station 19 as shown in Figure 4. Due to inherent damping in the specimen, the test was restricted to fundamental vibration mode with the impact hammer. Tests were conducted for all types of specimen with the three separate boundary conditions and the results recorded.

Figures 5-7 indicate the multi-layered sandwich panels subjected to modal excitation under different boundary conditions such as (a) cantilever, (b) two sides fixed and (c) all sides fixed respectively. 


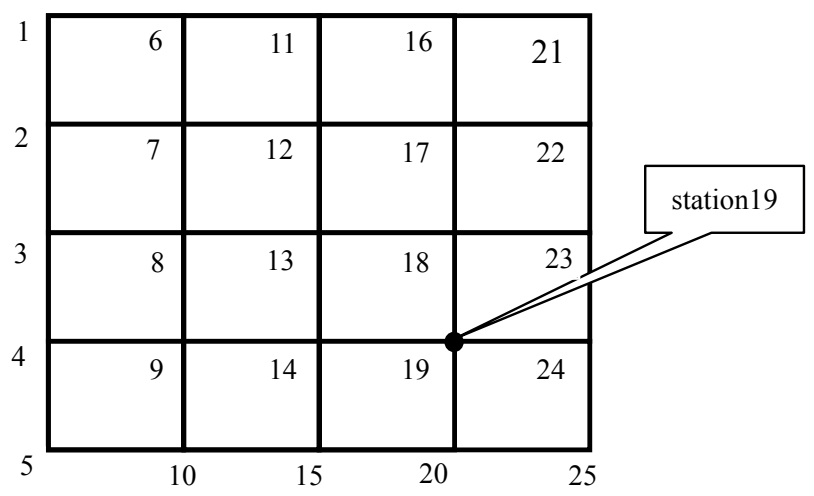

Figure 4. Grid points for impact and accelerometer location.

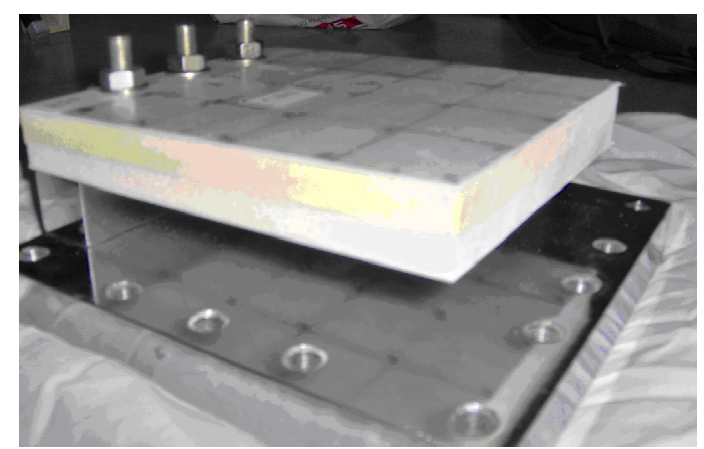

Figure 5. Cantilever condition.

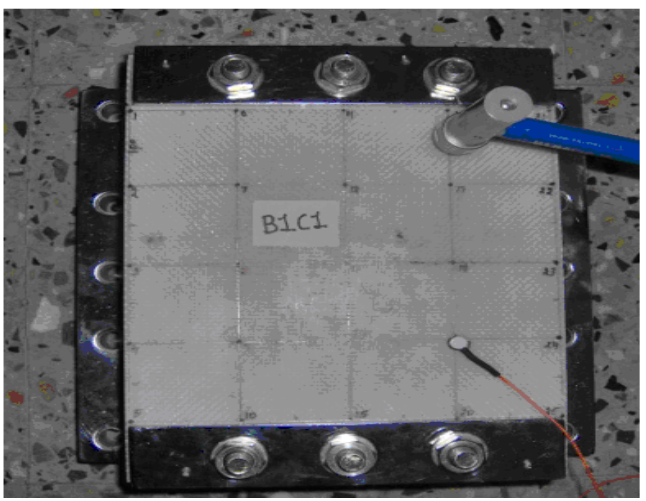

Figure 6. Two end fixed condition.

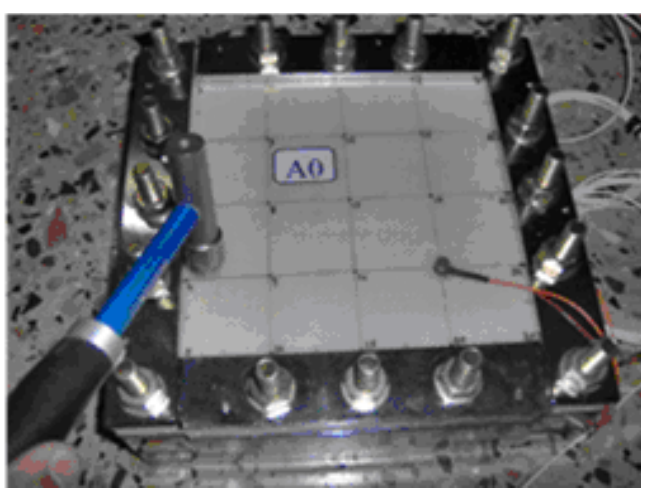

Figure 7. All end fixed condition.

\section{Results}

Table 3 provided below indicates the natural frequencies of the test specimens obtained by both experimental and FEA methods. Figure 8 shows a typical mode shape of multilayered sandwich panel with cantilever condition.

The results in Table $\mathbf{3}$ and Figures $\mathbf{9}$ and $\mathbf{1 0}$ indicate the effect of boundary conditions on the natural frequency of the Multilayer polyurethane foam sandwich panels. By strike method, the first three natural frequencies and their related damping ratios were investigated. Graphs for monolayer and multilayer sandwich panels for "frequency vs. mode number" for foam density of $56 \mathrm{~kg} / \mathrm{m}^{3}$ have been indicated in Figures 9 and 10. A similar trend has been observed for other combinations of sandwich panels as well. Finite Element simulation has also been carried out and results recorded in Table 3 . The results are found to be in good agreement with the experimental results.

The sandwich panels with viscoelastic cores represent the physical application of the viscoelastic integrated damping treatment concept. The panels associate different materials, each having a specific structural contribution. The stiff material of the outside faces guarantees the

Table 3. Results of modal testing and FEA.

\begin{tabular}{|c|c|c|c|c|c|}
\hline \multirow{2}{*}{ Sl. No } & \multirow{2}{*}{$\begin{array}{c}\text { Specimen } \\
\text { Designation }\end{array}$} & \multirow{2}{*}{$\begin{array}{l}\text { Boundary } \\
\text { Conditions }\end{array}$} & \multicolumn{2}{|c|}{ EXPERIMENTAL } & \multirow[t]{2}{*}{ FEA } \\
\hline & & & Frequency $\mathrm{Hz}$ & \% Damping & \\
\hline 1. & A0 & & 506 & 0.75 & 505 \\
\hline 2. & B0 & & 558 & 0.54 & 555 \\
\hline 3. & $\mathrm{CO}$ & & 1090 & 0.69 & 1137 \\
\hline 4. & $\mathrm{~A} 0 \mathrm{~B} 0$ & $-C-c$ & 607 & 1.32 & 624 \\
\hline 5. & $\mathrm{~A} 0 \mathrm{C} 0$ & & 777 & 1.14 & 669 \\
\hline 6. & $\mathrm{~B} 0 \mathrm{C} 0$ & & 883 & 1.19 & 855 \\
\hline 7. & A1 & & 330 & 0.28 & 357 \\
\hline 8. & B1 & & 350 & 0.89 & 392 \\
\hline 9. & $\mathrm{C} 1$ & & 709 & 1.03 & 801 \\
\hline 10. & A1B1 & & 396 & 1.37 & 442 \\
\hline 11. & $\mathrm{~A} 1 \mathrm{C} 1$ & & 484 & 1.48 & 474 \\
\hline 12. & $\mathrm{~B} 1 \mathrm{C} 1$ & & 557 & 1.79 & 535 \\
\hline 13. & A2 & & 77 & 0.69 & 67 \\
\hline 14. & $\mathrm{~B} 2$ & & 75 & 0.94 & 78 \\
\hline 15. & $\mathrm{C} 2$ & & 146 & 1.02 & 148 \\
\hline 16. & $\mathrm{~A} 2 \mathrm{~B} 2$ & & 84 & 1.24 & 88 \\
\hline 17. & $\mathrm{~A} 2 \mathrm{C} 2$ & & 97 & 1.58 & 92 \\
\hline 18. & $\mathrm{~B} 2 \mathrm{C} 2$ & & 109 & 1.91 & 114 \\
\hline
\end{tabular}




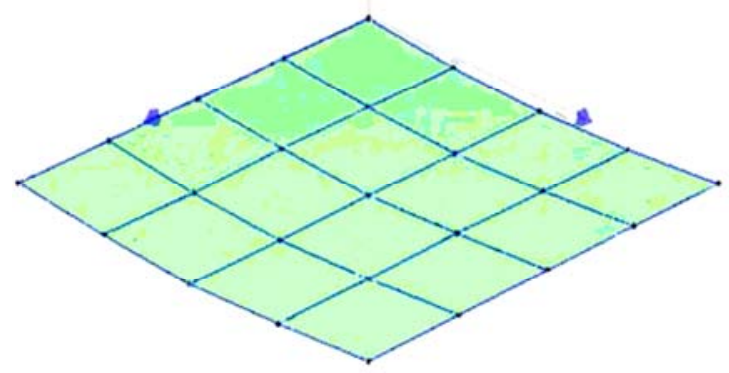

Figure 8. Typical mode shape of multilayered sandwich panels (Mode 1-Symmetric Bending).

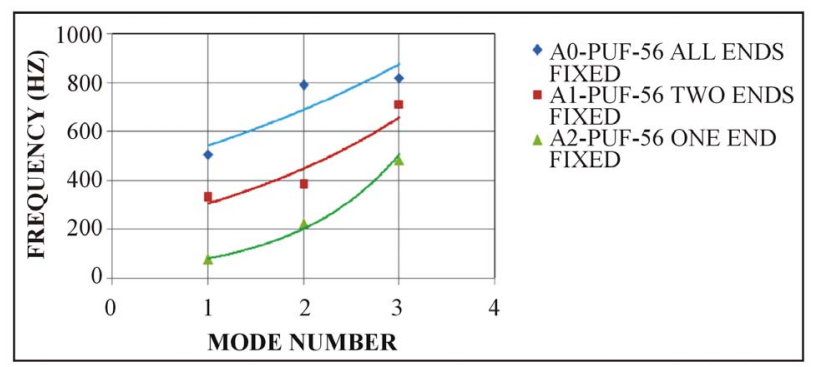

Figure 9. Frequency vs mode number for single layer sandwich construction.

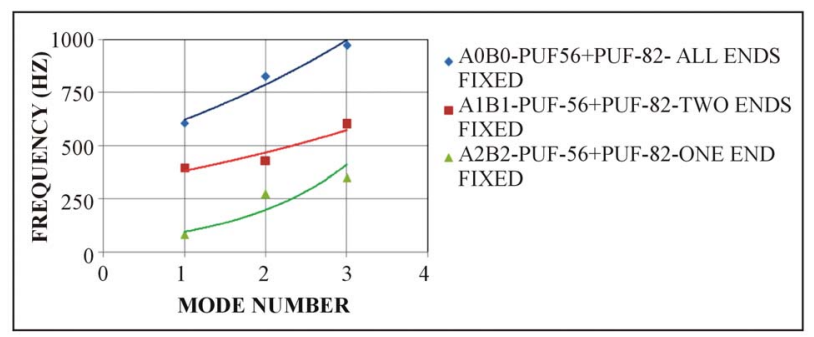

Figure 10. Frequency vs mode number for multilayer sandwich construction.

stiffness of the composite structure and the viscoelastic soft core provides the damping capability. The application of foam as core, specially the thick ones, into sandwich panels produces an important decoupling effect. This leads to a significant reduction of flexural stiffness of the sandwich panels as evidenced by experimental and numerical results.

To minimize such reduction of flexural stiffness, the portioning of the core layer into multiple layers, separated by thin constraining viscoelastic layers in the sandwich core, is considered. Given the advantage of the application of multiple layers of sandwich core, the potential use of different viscoelastic materials in order to obtain a range of damping treatment has been analyzed. It can be observed from Table 3 that for mono-layered sandwich panels, the modal damping is very low as compared to multilayered sandwich panels. Hence, the results of this experimental study demonstrate the applicability of two multilayered configurations of core with different densities, resulting in improved damping.

\section{Research Findings}

During this investigation on dynamic response of Multilayer polyurethane foam with GFRP laminate as face sheet, following inferences were drawn:

1) For the same mass and geometry, with change in the boundary conditions, natural frequency increased several folds.

2) Dynamic responses of the sandwich panels can be altered by modifying the number of core layers and also by varying core densities.

3) Finite Element simulation can be implemented for free vibration analysis to predict the natural frequencies, and mode shapes of the panels accurately and efficiently.

4) The results obtained from FEA were found to be in good agreement with the experimental results to both monolayer and multilayer sandwich panels.

\section{Acknowledgements}

The authors thankfully acknowledge the Management, Principal and Head of the Department, Mechanical Engineering, RV College of Engineering, Bangalore for their constant support and encouragement during this work. This research received no specific grant from any funding agency in the public, commercial, or not-for-profit sectors.

\section{REFERENCES}

[1] P. H. W. Tsang and P. A. Lagace, "Failure Mechanisms of Impact-Damaged Sandwich Panels under Uniaxial Compression," 35th AIAA/ASME/ASCE/AHS/ASC Structures, Structural Dynamics and Materials Conference, Hilton Head, 18-20 April 1994, pp. 745-754.

[2] P. A. Lagace and J. E. Williamson, "Contribution of the Core and Facesheet to the Impact Damage Resistance of Composite Sandwich Panels," 10th DOD/NASA/FAA Conference on Fibrous Composites in Structural Design, Hilton Head, April 1994, pp. II53-II74.

[3] M. F. Aly et al., "Experimental Investigation of the Dynamic Characteristics of Laminated Composite Beams," International Journal of Mechanical \& Mechatronics IJMME-IJENS, Vol. 10, No. 3, pp. 41-48.

[4] Z. K. Awad, T. Aravinthan and Z. G. Yan and F. Gonzalez, "Investigation of Frequency Characteristics of GFRP/ Phenolic Sandwich Beams," Southern Region Engineering Conference, 11-12 November 2010, Toowoomba.

[5] J. E. Jam, B. Eftari and S. H. Taghavian, "Better Predicting the Dynamic Response of Sandwich Panels," Plastic Research, Society of Plastics Engineers.

[6] Z. Li "Vibration and Acoustical Properties of Sandwich Composite Materials," A Dissertation Submitted to the Graduate Faculty of Auburn University in Partial Fulfillment of the Requirements for the Degree of Doctor of 
Philosophy Auburn, 2006.

[7] J. Xiong, A. Vaziri, L. Ma, J. Papadopoulos and L. Z. Wu, "Compression and Impact Testing of Two-Layer Composite Pyramidal-Core Sandwich Panels," Composite Structures, Vol. 94, No. 2, 2012, pp. 793-801.

[8] M. Matter, T. Gmür, J. Cugnoni and A. Schorderet, "Identification of the Elastic and Damping Properties in Sandwich Structures with a Low Core-To-Skin Stiffness Ratio," Composite Structures, Vol. 93, No. 2, 2011, pp. 331341. doi:10.1016/j.compstruct.2010.09.009

[9] Q. L. Liu and Y. Zhao, "Prediction of Natural Frequencies of a Sandwich Panel Using Thick Plate Theory," Journal of Sandwich Structures and Materials, Vol. 3, No. 4, 2001, pp. 289-309.

[10] A. Shahdin, L. Mezeix, C. Bouvet, J. Morlier and Y. Gourinat, "Fabrication and Mechanical Testing of Glass Fiber Entangled Sandwich Beams: A Comparison with Honeycomb and Foam Sandwich Beams," Composite Structures, Vol. 90, No. 4, 2009, pp. 404-412. doi:10.1016/j.compstruct.2009.04.003

[11] H. L. Fan, W. Yang and Q. Zhou, "Experimental Research of Compressive Responses of Multi-Layered Woven Textile Sandwich Panels under Quasi-Static Loading," Com- posites Part B: Engineering, Vol. 42, No. 5, 2011, pp. 1151-1156. doi:10.1016/j.compositesb.2011.03.008

[12] K. P. Dharmasena, D. Queheillalt, H. N. G. Wadley, et al., "Dynamic Response of a Multilayerprismatic Structure to Impulsive Loads Incident from Water," International Journal of Impact Engineering, Vol. 36, No. 4, 2009, pp. 632-643. doi:10.1016/j.ijimpeng.2008.06.002

[13] W. Hng, K. P. Dharmasena, Y. Chen, et al., "Compressive Response of Multilayered Pyramidal Lattices during Underwater Shock Loading," International Journal of Impact Engineering, Vol. 35, No. 9, 2008, pp. 1102-1114. doi:10.1016/j.ijimpeng.2007.06.009

[14] S. C. Mohanty, "Finite Element Modeling of a Multilayered Sandwich Beam with Viscoelastic Core for Vibration Analysis," International Conference on Modeling, Simulation and Control IPCSIT, Vol. 10, 2011, IACSIT Press.

[15] B. C. Nakra, "Vibration Control in Machines and Structures Using Viscoelastic Damping," Journal of Sound and Vibration, Vol. 211, No. 3, 1998, pp. 449-465. doi:10.1006/jsvi.1997.1317 